\title{
Study of dye desorption mechanism of bone char utilizing different regenerating agents
}

\author{
Dayane Samara de Carvalho Coltre ${ }^{1,2}$. Caroline Apoloni Cionek ${ }^{2}$. Joziane Gimenes Meneguin ${ }^{3}$. \\ Celso Hissao Maeda ${ }^{1}$ (1) - Mateus Urias Cerdeira Braga ${ }^{1}$. Augusto Cândido de Araújo ${ }^{3}$. Gisele de Freitas Gauze ${ }^{3}$. \\ Maria Angélica Simões Dornellas de Barros ${ }^{1} \cdot$ Pedro Augusto Arroyo ${ }^{1}$
}

Received: 12 December 2019 / Accepted: 18 November 2020 / Published online: 4 December 2020

(c) Springer Nature Switzerland AG 2020

\begin{abstract}
The reactive blue BF-5G dye is used on the textile industry due to its bifunctional characteristic that enables a higher interaction between the dye and the fabric fibers. Nonetheless, the dyeing produces a high amount of wastewater and the removal of the dye with a regenerative adsorbent is an attractive cost-efficient process. Therefore, the aim of this work was to evaluate the desorption mechanism of the reactive blue BF-5G dye on bone char employing different regenerating agents at different $\mathrm{pH}$ conditions. Aqueous solutions with $\mathrm{pH}$ from 2 to 12 and alcoholic solutions of methyl, ethyl and isopropyl were used as regenerating agents in a batch system with constant temperature. The highest regeneration efficiency with water was at $\mathrm{pH}=12(\sim 2.0 \%)$ which was low due to alkaline conditions. The increase of negative charges on the surface of the bone char at $\mathrm{pH}=12$, generated electrostatic repulsion between the adsorbent and the dye, followed by its desorption. In addition, with increasing concentration of sodium hydroxide, the desorption efficiency is reduced due to the fact that $\mathrm{Na}^{+}$compensate the negative charge generated on the surface of the bone char. On the other hand, since dye desorption using organic regenerating agents is due to replacement of the dye molecules by an organic one, an increase in regeneration was observed. The highest regeneration efficiencies of $\sim 21.0 \%$ and $19.5 \%$ were obtained using isopropyl and ethyl alcohols, respectively. These results indicate that the strong interactions between the dye and the bone char surface were not broken by the regenerating agents studied, thus achieving low dye desorption efficiency. Therefore, desorption efficiencies are related only to the regeneration of weaker interactions on bone char surfaces for these systems, in batch conditions.
\end{abstract}

Keywords Potential electrostatic map · Reactive blue BF-5G · Desorption kinetics · Solvation effect

\section{Introduction}

The textile, dyestuffs, paper and polymers industries employ dyes during the manufacture of their products and, consequently, are considered to produce a substantial volume of wastewater contaminated by unreacted and excess dye, markedly by an intense color. Due to its easy naked eye identification, dyes might have been the first pollutant to be known in wastewater. In this sense, textile industries are major dyes polluting sources, mainly synthetic dyes. For instance, to process $1 \mathrm{~kg}$ of dyed fabrics, approximately $100 \mathrm{~L}$ of water are required [1].

Usually, cationic, acid, direct, disperse, sulfur and reactive dyes are used in the textile industry [2], with reactive dyes consumption rapidly growing due to its increasing application in cellulosic fibers. However, since reactive

Celso Hissao Maeda, celsohissaomaeda@gmail.com | ${ }^{1}$ Department of Chemical Engineering, Laboratory of Adsorption and lon Exchange, State University of Maringá, Colombo Avenue 5790, CEP 87020-900, Maringá, Paraná, Brazil. ²Department of Textile Engineering, Federal Technological University of Parana, Marcílio Dias Street 635, CEP 86812-460, Apucarana, Paraná, Brazil. ${ }^{3}$ Department of Chemistry, State University of Maringá, Colombo Avenue 5790, CEP 87020-900, Maringá, Paraná, Brazil. 
dyes have low rates of fixation, it is often used as a high concentrated solution in order to attain the required dying quality standards, thus leading to the formation a concentrated dye-contaminated liquid effluent. Additionally, dyes are not easily biodegradable $[3,4]$. The contaminated effluent generated by textile industries exhibits intense color, are toxic even in very small concentrations and may cause interference in the process of photosynthesis and the destruction of the food chain in aquatic ecosystems [5].

In order to mitigate environmental problems, many methods have been used to remove dyes from textile effluents, such as coagulation, membrane separation processes, electrochemical, oxidation, reverse osmosis, and microbial aerobic and anaerobic degradation [6]. Nevertheless, these methods are not considered efficient $[1,2]$ and adsorption has proven to be an excellent process for the treatment of colored industrial effluents, offering significant economic and environmental advantages when compared to conventional methods. Adsorption process advantages include low cost, availability, profitability, efficiency, and ease of operation [7, 8], but an appropriate adsorbent is mandatory and activated carbon is the most commonly adsorbent used for color removal from textile effluent [3, 9-12]. However, as all adsorbents, activated carbon has a finite capacity for dye adsorption. Thus, the regeneration of saturated carbons becomes one of the most important issues in textile wastewater treatment, since the reuse of activated carbons could determine the economic viability of the adsorption process [13].

Different methods for regenerating activated carbon, such as thermal regeneration [14], regeneration by wet oxidation [15], chemical regeneration [16, 17], electrochemical regeneration [18] and regeneration by ultrasound [19] have been investigated. Among these, chemical regeneration deserves a special attention since it offers significant advantages, such as: (i) it can be performed in situ, thus eliminating unloading, transporting and reconditioning of the adsorbent; (ii) the loss of carbon resulting from thermal regeneration is eliminated; (iii) the recovery of the adsorbate is possible; and (iv) with the appropriate conditions, the number of chemical regeneration cycles can be increased [20].

Chemical regenerating agents can be classified in two groups: inorganic chemicals and organic solvents. Sodium hydroxide is an example of an important inorganic regenerating agent since it is closely linked to the process $\mathrm{pH}$ [16]. Indeed, Mahmoodi et al. [21] evaluated the effect of the $\mathrm{pH}$ in the desorption of three acid dyes and found that the number of adsorption sites that were negatively charged increased as the $\mathrm{pH}$ of desorption increased. Regarding the organic solvents with different polarities, they compete with the dye for adsorption sites on the surface of the activated carbons, leading to a dye desorption
$[22,23]$. Therefore, the organic solvents may replace the previously adsorbed dye molecules, enabling the adsorbent to be reused.

It is difficult to find in literature studies that focus on dye desorption. Many of the works that have been found mainly study the adsorption step and fall short when it comes to the desorption one $[5,21,24,25]$. Therefore, the objective of this work was to evaluate the Reactive Blue BF-5G dye desorption mechanism on bone char employing different regenerating agents at different $\mathrm{pH}$ conditions.

\section{Experimental}

\subsection{Adsorbent, adsorbate and chemicals}

The company Bonechar Carvão do Brasil Ltda (Brazil) gentle donated the bone char utilized in this work. Before experiments, the material was sieved to obtain particles with a mean diameter of $0.725 \mathrm{~mm}$.

The Reactive Blue BF-5G dye (C.I. Reactive Blue 203; $M W=1051 \mathrm{~g} \mathrm{~mol}^{-1}$ ) $[26,27]$, was provided by Texpal Chemical Industry Ltda. Its chemical structure is shown in Fig. 1. The molecular structure of such organic compounds includes four anionic $\mathrm{SO}_{3}^{-}$groups balanced by four $\mathrm{Na}^{+}$ cations. These groups deserve special attention because their presence results in classification of the dye as anionic. Moreover, the anionic charge may be easily attracted to the adsorbent according to the $\mathrm{pH}$ of the fluid phase [9, 28].

Deionized water was produced using a PermutationRO0210 equipment. Sodium hydroxide was acquired from Nuclear company. Methyl, ethyl and isopropyl alcohols were acquired from Fmaia company. All chemicals were used as acquired or diluted and were of analytical grade.

\subsection{Adsorbent characterization}

\subsubsection{X-ray diffraction (XRD)}

The identification of crystalline phases in the bone char was carried out by X-ray diffraction analysis in a Shimadzu $\mathrm{X}$-ray diffractometer, model D6000, with CuKa radiation. Measurements were made using a step-scanning technique with the diffraction angle ranging from $4 \leq^{\circ} 2 \theta \leq 80$ and scan speed of $0.1^{\circ} \mathrm{min}^{-1}$.

\subsubsection{Adsorption/desorption of $\mathrm{N}_{2}$}

The textural characterization of the bone char was performed using a Micromeritics ASAP 2020 Physisorption equipment. Initially, the bone char sample was weighed 
<smiles>COc1cc(S(=O)(=O)CCOS(=O)(=O)[O-])c(OC)cc1N=Nc1c(S(=O)(=O)[O-])cc2cc(S(=O)(=O)[O-])c(N=Nc3ccc(S(=O)(=O)CCOS(=O)(=O)[OH2+])cc3)c(N)c2c1O</smiles>

Fig. 1 Chemical structure of Reactive Blue BF-5G dye

and pretreated at $300^{\circ} \mathrm{C}$ for $1 \mathrm{~h}$ under vacuum. Then, the adsorption/desorption of $\mathrm{N}_{2}$ measurements were conducted with liquid nitrogen with a temperature of $-196^{\circ} \mathrm{C}$ (77 K). From the obtained isotherm, the specific surface area and average pore diameter were determined using the BET method, the pore volume distribution was calculated by the BJH method, the volume of micropores by the t-plot method and total pore volume as defined by the corresponding amount of adsorbed $\mathrm{N}_{2}$ with relative pressure $\mathrm{p} / \mathrm{p}_{0}=0.99$.

\subsection{3 $\mathrm{pH}$ of point zero charge $\left(\mathrm{pH}_{\mathrm{PZC}}\right)$}

The 11-points methodology was used for determining the $\mathrm{pH}$ of point of zero charge $\left(\mathrm{pH}_{\mathrm{PZC}}\right)$ [29] of the bone char using a mass-volume ratio of $1.0 \mathrm{~g} \mathrm{~L}^{-1}$. Briefly, the experiments were carried out by immersing the adsorbent in an aqueous solution of $\mathrm{NaCl}$ with 11 different initial $\mathrm{pH}(2$, $3,4,5,6,7,8,9,10,11,12)$, adjusted with $\mathrm{HCl}$ or $\mathrm{NaOH}$ solutions $\left(0.1 \mathrm{~mol} \mathrm{~L}^{-1}\right)$. After $24 \mathrm{~h}$ of stirring $(80 \mathrm{rpm})$ with constant temperature of $25^{\circ} \mathrm{C}$, the $\mathrm{pH}$ of each sample was measured using a $\mathrm{pH}$ meter Thermo Scientific model Orion Dual Star.

\subsubsection{Theoretical calculations of charge distribution in the dye molecule}

Theoretical calculations were performed with GAMESSUS package program [30]. To investigate the preferential conformations of reactive blue BF-5G dye, the possible conformations were optimized in AM1, PM3 and PM6 and solvation effects were included with IEF-PCM. The dielectric constant of water stored in the program database. Electrostatic potential surface of the most stable structure was generated considering medium $\mathrm{pH}$ of 2 (form 1), 7 (form 2) and 10 (form 3) [31, 32].

\subsubsection{Potentiometric titration for the determination of dye pKa}

The potentiometric titration consists of determining the final point of a titration process by means of $\mathrm{pH}$ measurement and the detection of the final point of the titration can be easily noted by examining the titration curve, with the final point being the inflection point of the curve [33]. To determine the pKa of the dye, $100 \mathrm{~mL}$ of a $10 \mathrm{mg} \mathrm{L}^{-1}$ dye solution was placed in a beaker with constant magnetic stirring. A pH meter was coupled to the beaker and the initial $\mathrm{pH}$ was adjusted to 2 by adding a $0.01 \mathrm{~mol} \mathrm{~L}^{-1} \mathrm{HCl}$ solution. Then, the acidic dye solution was slowly titrated with $\mathrm{NaOH}\left(0.01 \mathrm{~mol} \mathrm{~L}^{-1}\right)$ using a burette and the $\mathrm{pH}$ variation was measured. A plot of volume of $\mathrm{NaOH}$ added versus $\mathrm{pH}$ measured was plotted. Subsequently, a graph of the first and second derivative of the measured $\mathrm{pHs}$ were plotted which, accurately, establishes the final point (inflection point) of the titration and, consequently, determines the dye pKa as being half of that value [34]. 


\subsection{Preparation of saturated activated carbon}

Before starting the desorption test, the bone char was saturated by adding $1.5 \mathrm{~g}$ of adsorbent in an Erlenmeyer containing $150 \mathrm{~mL}$ of a $4000 \mathrm{mg} \mathrm{L}^{-1}$ dye aqueous solution ( $\mathrm{pH}_{\text {initial }}$ approximately 5.6-6.2). The flask was shaken in a Dubnoff bath (Nova Ética, model 304 $\mathrm{DE})$ with controlled temperature $\left(30^{\circ} \mathrm{C}\right)$ at $80 \mathrm{rpm}$ until adsorption equilibrium ( $36 \mathrm{~h}$ ). After that, the saturated bone char was separated from the solution by filtration (Unifil filter paper C42 blue band, 1-2 $\mu \mathrm{m}$ ) and dried at $40{ }^{\circ} \mathrm{C}$ until constant weight. The absorbance of the filtered dye solution was measured in a spectrophotometer (Shimadzu, model UV-1203) with $\lambda=620 \mathrm{~nm}$. The experiment was performed in duplicate and taking the average of the results. Then, the concentration of the dye solution was calculated using the Lambert-Beer law [35]. The amount of dye removed by adsorption from the dye solution was calculated using the Eq. 1.

$\mathrm{q}_{\mathrm{ads}}=\frac{\mathrm{V}}{\mathrm{m}} \cdot\left(\mathrm{C}_{0}-\mathrm{C}_{\mathrm{ads}}\right)$

where $\mathrm{q}_{\mathrm{ads}}$ is the amount of dye adsorbed at equilibrium $\left(\mathrm{mg} \mathrm{g}^{-1}\right), \mathrm{C}_{0}$ is the initial concentration of dye in liquid phase $\left(\mathrm{mg} \mathrm{L}^{-1}\right), \mathrm{C}_{\mathrm{ads}}$ is the concentration of dye in the liquid phase at equilibrium conditions $\left(\mathrm{mg} \mathrm{L}^{-1}\right), \mathrm{V}$ is the volume of dye solution $(\mathrm{L})$, and $\mathrm{m}$ is the mass of bone char $(\mathrm{g})$.

The amount of dye adsorbed at equilibrium $\left(\mathrm{q}_{\mathrm{ads}}\right)$ by bone char was $105.5 \mathrm{mg} \mathrm{g}^{-1}$. For the kinetics of desorption and mechanisms experiments, the saturated samples of bone char were prepared as describe here.

\subsection{Kinetics of desorption}

Kinetic of desorption was evaluated using deionized water (without $\mathrm{pH}$ adjustment), deionized water with $\mathrm{pH} 2-12$ adjusted with $\mathrm{HCl}$ or $\mathrm{NaOH}\left(0.1 \mathrm{~mol} \mathrm{~L}^{-1}\right)$, methyl alcohol 50\% $\left(\mathrm{v} \mathrm{v}^{-1}\right)$, ethyl alcohol 50\% $\left(\mathrm{v} \mathrm{v}^{-1}\right)$ and isopropyl alcohol $50 \%\left(v v^{-1}\right)$ as regenerating agents. These solutions were chosen due to the significant results reported in the literature $[4,5,21,22,36,37]$.

The desorption kinetic experiment was performed by adding $0.2 \mathrm{~g}$ of saturated bone char sample to an Erlenmeyer and, then, adding $20 \mathrm{~mL}$ of the respective regenerating solution. The flasks were shaken in a Dubnoff bath (Nova Ética, model 304 TPA) with controlled temperature $\left(30^{\circ} \mathrm{C}\right)$ at $80 \mathrm{rpm}$ for $12 \mathrm{~h}$. The flasks were picked up from the shaker at predetermined time and its content was immediately filtered by means of filtration using qualitative paper blue ribbon grade (Unifil C42 1-2 $\mu \mathrm{m})$. The experiments were performed in duplicate and taking the average of the results. The absorbance of the filtered dye solution was measured by UV/vis spectrophotometer (Shimadzu, model UV-1203) at predetermined wavelengths $(600 \mathrm{~nm}$ for dye diluted in $\mathrm{NaOH}$ solution, $620 \mathrm{~nm}$ for dye diluted in deionized water, and $625 \mathrm{~nm}$ for dye diluted in organic solvents).

The amount of dye desorbed from the bone char as a function of time was determined using Eq. 2.

$\mathrm{q}_{\mathrm{dt}}=\frac{\left(C_{\mathrm{dt}}-\mathrm{V}_{\mathrm{r}}\right)}{\mathrm{m}_{\mathrm{s}}}$

where $q_{d t}$ is the amount of dye desorbed at time $t\left(\mathrm{mg} \mathrm{g}^{-1}\right)$, $C_{d t}$ is the desorbed dye concentration in the liquid phase at time $t\left(\mathrm{mg} \mathrm{L}^{-1}\right), \mathrm{V}_{\mathrm{r}}$ is the volume of regenerating agent solution $(L)$ and $m_{s}$ is the mass of bone char saturated sample $(\mathrm{g})$.

Therefore, the desorption efficiency as a function of time was determined by Eq. 3 .

$E_{d t}=\frac{q_{d t}}{q_{a d s}} \cdot 100$

where $E_{d t}$ is the desorption efficiency at a time $t(\%)$ and $\mathrm{q}_{\text {ads }}$ is the amount of dye adsorbed at equilibrium $\left(\mathrm{mg} \mathrm{g}^{-1}\right)$.

For the experiments using deionized water with adjusted $\mathrm{pH}$ and the chemical regenerating solvents, the parameters $\mathrm{q}_{\mathrm{dt}}, \mathrm{C}_{\mathrm{dt}}$ and $\mathrm{E}_{\mathrm{dt}}$ in Eqs. 2 and 3 were replaced by their respective values in equilibrium conditions, namely $\mathrm{q}_{\mathrm{dw}}, \mathrm{C}_{\mathrm{dw}}$ and $\mathrm{E}_{\mathrm{dt}}$ for deionized water with adjusted $\mathrm{pH}$ and $\mathrm{q}_{\mathrm{dc}} \mathrm{C}_{\mathrm{dc}}$ and $\mathrm{E}_{\mathrm{dc}}$ for the chemical regenerating solvents.

\subsection{FT-IR analysis}

Fourier transform infrared spectroscopy was carried out using a Shimadzu spectrometer, model IRPrestige- 21 . Initially, the bone char samples were dried at $100^{\circ} \mathrm{C}$ for $12 \mathrm{~h}$, crushed and mixed with $\mathrm{KBr}$ in pellets. Spectra were recorded in the range of $400-4000 \mathrm{~cm}^{-1}$ averaging 128 scans with $4 \mathrm{~cm}^{-1}$ of resolution.

\section{Results and discussion}

\subsection{Characterization}

\subsubsection{X-ray diffractometry (XRD)}

Bone char is composed of carbon atoms distributed throughout the porous structure of hydroxyapatite [38] corresponding to, approximately, $10 \%$ of carbon atoms and mainly calcium phosphate $(90 \%)$ corresponding to the hydroxyapatite structure [39]. Therefore, the XRD of the bone char shown in Fig. 2 revealed different peaks 


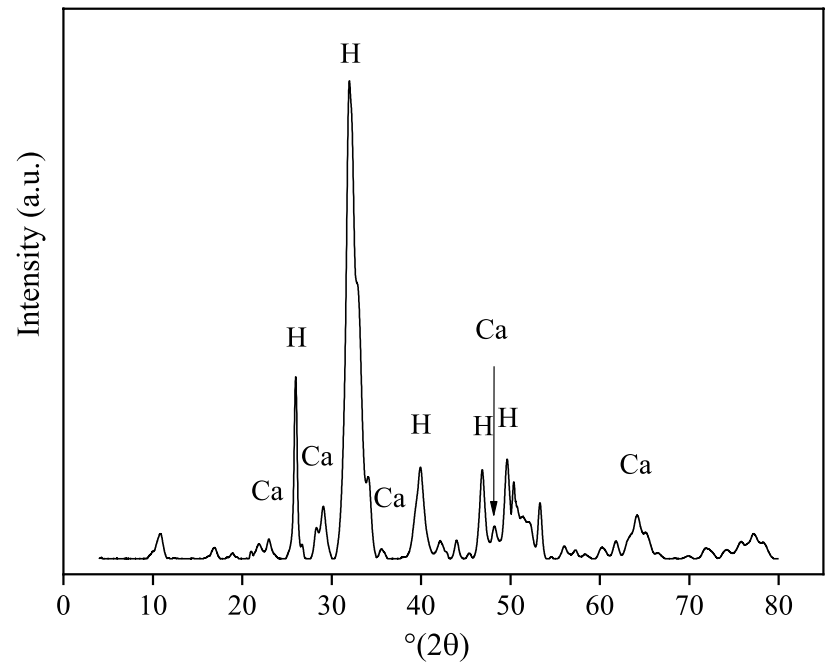

Fig. 2 Diffractogram of bone char: $(\mathrm{H})$ hydroxyapatite; and (Ca) calcium carbonate

instead of the commonly ones found in activated carbon materials such as corn stalk-based activated carbons [40] or coffee grounds activated carbons [41]. Nonetheless, the XRD pattern agree with the diffractograms of bone char from fish bones [42] and from sheep leg bones [43].

The diffractogram of the bone char (Fig. 2) showed that the diffraction peaks at ${ }^{\circ}(2 \theta)=25.9,31.7,40,46.7$ and 49.5 are characteristic of the hydroxyapatite $(\mathrm{H})$, $\mathrm{Ca}_{10}\left(\mathrm{PO}_{4}\right)_{6}(\mathrm{OH})_{2}$, and the peaks at ${ }^{\circ}(2 \theta)=23.0,29.4,36.0$, 48.5 and 64.7 are due to calcite structure $(\mathrm{Ca}), \mathrm{CaCO}_{3}$ [44], which is in accordance with the literature [38, 39, 45-49].

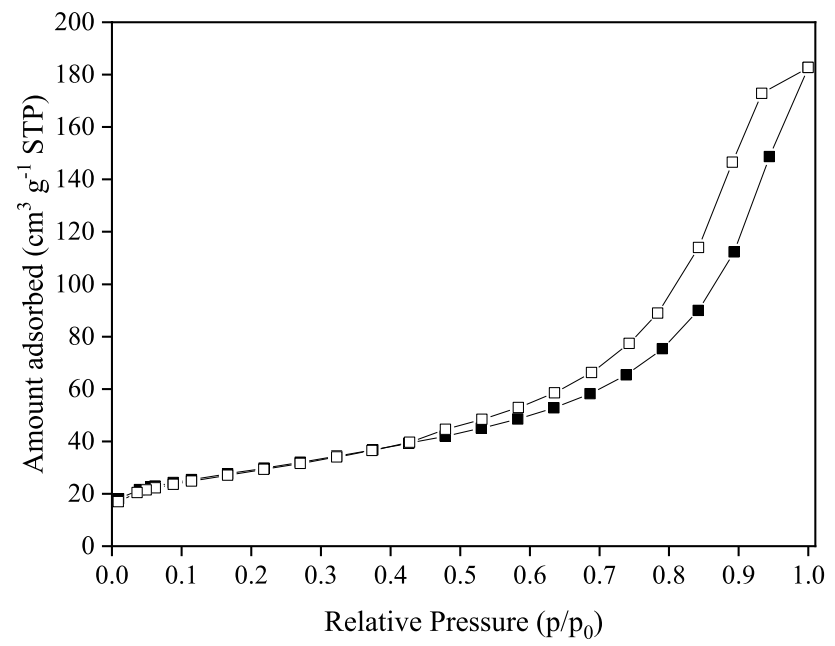

Fig. 3 Nitrogen isotherms of bone char: (filled square) adsorption; and (open square) desorption

\subsubsection{Physisorption of $\mathrm{N}_{2}$}

The physisorption of $\mathrm{N}_{2}$ for the bone char sample is shown in Fig. 3. The obtained adsorption/desorption isotherm is classified as a type-IV isotherm, whereas the hysteresis is of the type $\mathrm{H} 3$, indicating the predominance of mesopores in the form of parallel plates [50].

The distribution of pore size is another important textural characteristic for the bone char, and adsorbents in general, and it is presented in Fig. 4. The distribution of pores size in the bone char observed was, approximately, between 50 and $300 \AA$, meaning the predominance of mesopores in the sample. This mesopores predominance favors the accessibility of dye molecules (dimensions of $11 \times 28 \AA$ ) into adsorption sites inside the adsorbent porous structure.

The values of specific surface area, total pore volume, micropore volume and average pore diameter are shown in Table 1.

The bone char showed specific surface area of $103 \mathrm{~m}^{2} \mathrm{~g}^{-1}$. This fact is directly related to the average pore diameter of bone char, resulting in a lower surface area, which is in agreement with the large distribution of mesopore sizes (Fig. 4) and the type-IV nitrogen adsorption isotherm (Fig. 3). The results obtained herein are in accordance with the results present by Leyva-Ramos et al. [51] who characterized a bone char sample with specific surface area of $104 \mathrm{~m}^{2} \mathrm{~g}^{-1}$ and with total pore volume and average pore diameter of $0.30 \mathrm{~cm}^{3} \mathrm{~g}^{-1}$ and $111 \AA$, respectively. Maeda et al. [23] also characterized a bone char and the specific surface area and average pore diameter obtained were $109 \mathrm{~m}^{2} \mathrm{~g}^{-1}$ and $94 \AA$, respectively. Further, according to Table 1, it can be seen that there were no significant changes in the specific area, in the total pore

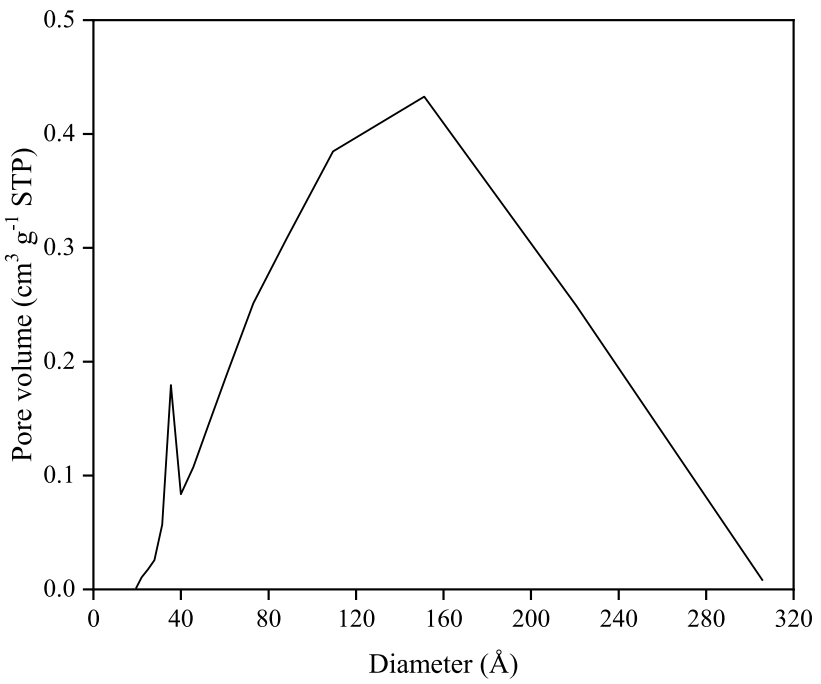

Fig. 4 Pores size distribution of bone char 
Table 1 Textural characterization of the adsorbent

\begin{tabular}{lllll}
\hline Parameter & \multicolumn{2}{l}{ Samples } & & \\
\cline { 2 - 5 } & Bone char & $\begin{array}{l}\text { Bone char } \\
+\end{array}$ & $\begin{array}{l}\text { Bone char } \\
+\end{array}$ & $\begin{array}{l}\text { Bone char } \\
+\end{array}$ \\
& & Ethyl alcohol & $\begin{array}{l}+ \\
\text { Isopropyl alcohol }\end{array}$ \\
\hline Specific surface area $^{\mathrm{a}}\left(\mathrm{m}^{2} \mathrm{~g}^{-1}\right)$ & 103 & 92 & 97 & 93 \\
Average pore diameter $^{\mathrm{a}}(\AA)$ & 97 & 117 & 114 & 116 \\
Total pore volume $^{\mathrm{b}}\left(\mathrm{cm}^{3} \mathrm{~g}^{-1}\right)$ & 0.284 & 0.272 & 0.280 & 0.272 \\
Micropore volume $^{c}\left(\mathrm{~cm}^{3} \mathrm{~g}^{-1} \mathrm{~g}\right)$ & 0.0026 & 0.0038 & 0.0069 & 0.0049
\end{tabular}

${ }^{\mathrm{a} B E T}$ method

${ }^{\mathrm{b}}$ single point

$c_{\text {t-plot method }}$
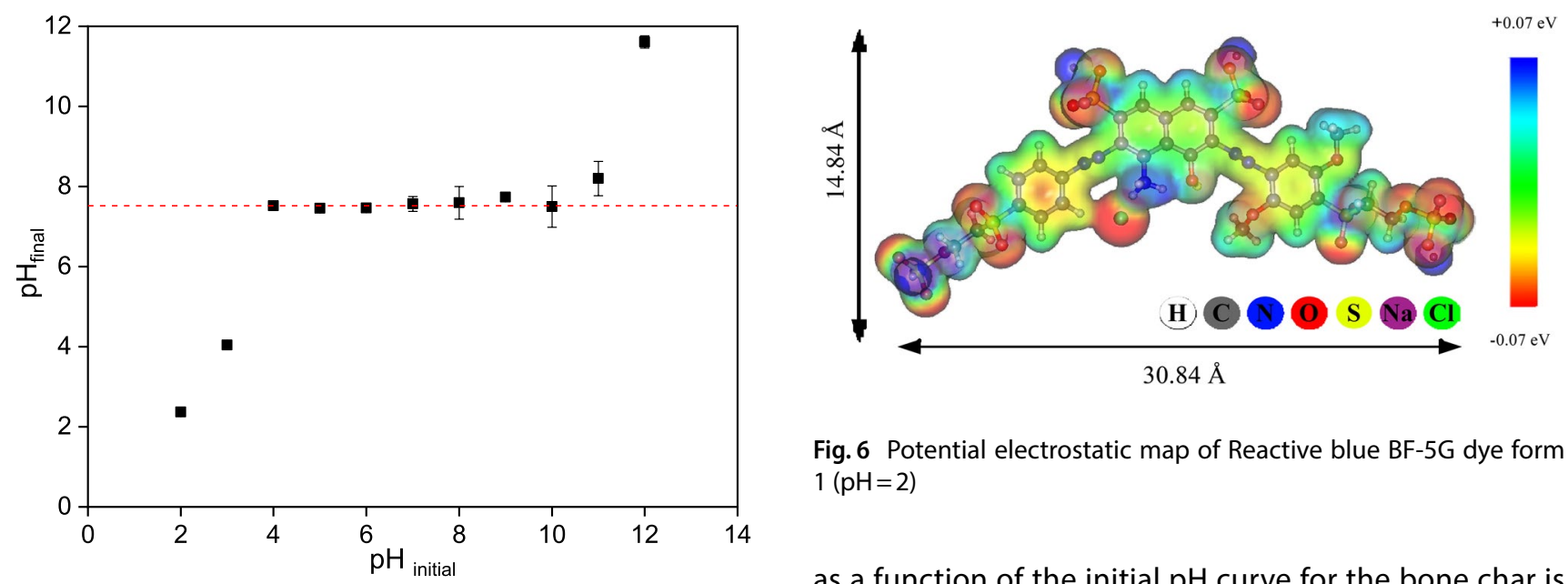

Fig. 6 Potential electrostatic map of Reactive blue BF-5G dye form $1(\mathrm{pH}=2)$

as a function of the initial $\mathrm{pH}$ curve for the bone char is shown in Fig. 5.

Therefore, the dye Reactive Blue BF- $5 \mathrm{G}$ will be adsorbed if the $\mathrm{pH}$ of the solution is less than the $\mathrm{pH}_{\mathrm{PZC}}$ of the adsorbent, which Fig. 5 revealed to be $7.5 \pm 0.1$. As the $\mathrm{pH}$ of the dye solution remained approximately 6 , i.e., less than the $\mathrm{pH}_{\mathrm{PCZ}}$ of the adsorbent studied, the adsorption process was favored, therefore it was not necessary to acidify the dye solution. Indeed, Al-Degs et al. [9] also observed that the adsorption capacity of the dyes Reactive Blue 2, Reactive Red 4 and Reactive Yellow 2, as an example of anionic dyes, on activated carbon, increased with the use of solution $\mathrm{pH}$ lower than the $\mathrm{pH}_{\mathrm{PZC}}$.

\subsubsection{Theoretical calculations of charge distribution in the dye molecule}

Considering that potential electrostatic maps were obtained through theoretical calculations, the semiempirical method PM6 efficiently described the geometry of Reactive blue BF-5G dye, since it takes into account the intramolecular hydrogen bonds, while the AM1 and PM3 disregard this important interaction. The Reactive blue BF-5G dye shows three main structures in $\mathrm{pH} 2,7$ and 10, as can be seen in Figs. 6, 7 and 8, respectively. 


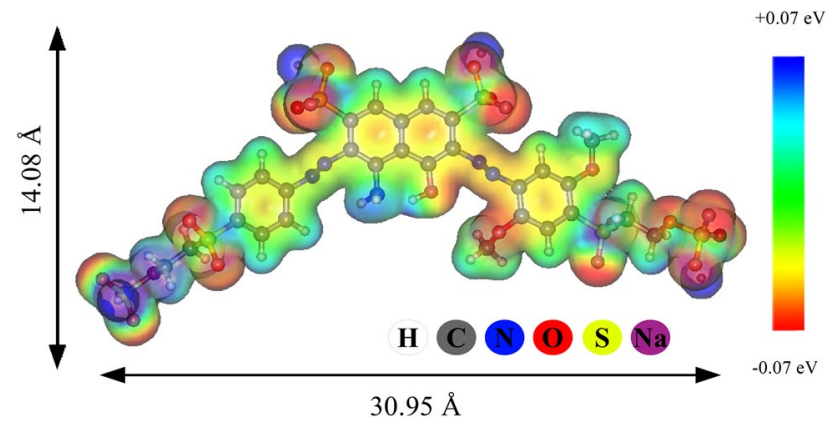

Fig. 7 Potential electrostatic map of Reactive blue BF-5G dye form $2(\mathrm{pH}=7)$

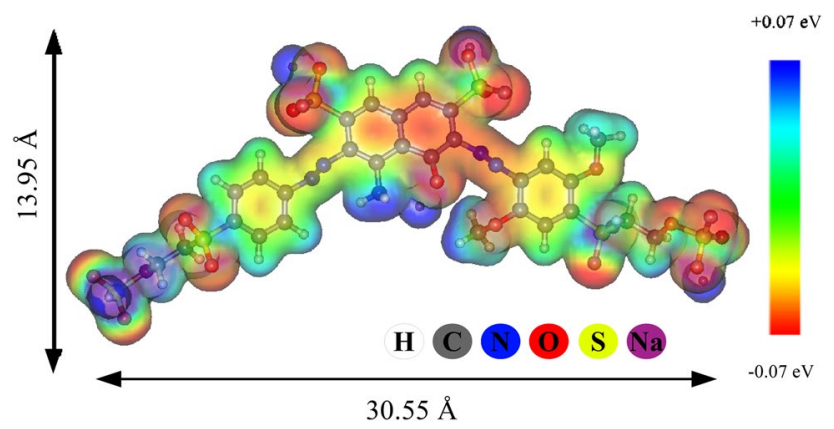

Fig. 8 Potential electrostatic map of Reactive blue BF-5G dye form $3(\mathrm{pH}=10)$

The electrostatic potential maps showed that the Reactive blue BF-5G dye has a high electron density, concentrated on the conjugated aromatic rings, in all studied $\mathrm{pHs}$. This suggests that by varying the $\mathrm{pH}$, changes in desorption could occur mainly by the influence of the chemical groups present in the bone char surface. Thus, a strong interaction is expected between the dye molecule and the adsorbent surface groups that will be hardly broken by regeneration agents due to the strong ionic character of these interactions.

In Figs. 6 up to 8 the dye molecules dimensions were calculated as varying from 30.55 to $30.95 \AA$ long and of 13.95 to $14.84 \AA$ in width. Therefore, for all pH studied, the dye molecules might be easily accommodated in bone char particle pores that have average diameter of $97 \AA$ (Table 1 and Fig. 4).

\subsubsection{Determination of dye pKa by potentiometric titration}

The determination of the pKa of the dye was based on the $\mathrm{pH}$ changes with addition of the $\mathrm{NaOH}$ titrant obtaining a titration curve, presented in Fig. 9, where it was possible to determine the points in which $\mathrm{pH}=\mathrm{pKa}$. The dye can be considered a diprotic acid with two dissociation constants whose experimental values of pKa were $\mathrm{pKa}_{1}=4.6$ and

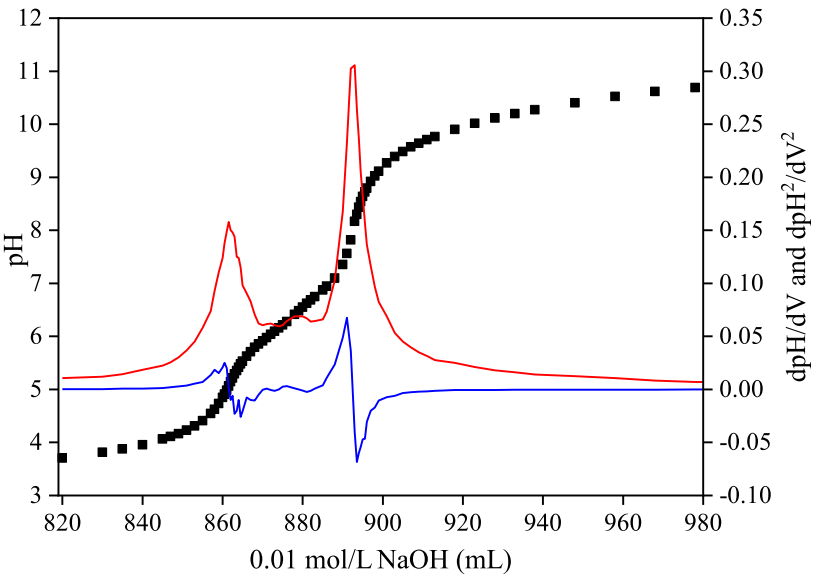

Fig. 9 Experimental data (filled square), first (red solid line) and second (blue solid line) derivatives from dye titration with $\mathrm{NaOH}$ $\left(0.01 \mathrm{~mol} \mathrm{~L}^{-1}\right)$

$\mathrm{pKa}_{2}=7.0$. The $\mathrm{pKa}_{1}=4.6$ corresponds to the deprotonation group $-\mathrm{NH}_{3}{ }^{+}$and at this $\mathrm{pH}$ half of the molecules are protonated $\left(-\mathrm{NH}_{3}{ }^{+}\right)$, as shown in Fig. 6 , and half are in the neutral form $\left(-\mathrm{NH}_{2}\right)$, according to Fig. 7, resulting in two species mainly in aqueous solution [52]. Then, when $\mathrm{pH}$ increases, the neutral form predominates. The $\mathrm{pKa}_{2}=7.0$ corresponds to the deprotonation of the - $\mathrm{OH}$ groups and it can be suggested that due to the proximity between the pKa values, a single pKa for the $-\mathrm{OH}$ group present on the naphthalene ring and the hydroquinone ring was observed experimentally (Fig. 9). Thus, when $\mathrm{pH}$ is equal to 7.0, half of the molecules are in the neutral form -OH (Fig. 7) and half are in the anionic form $-\mathrm{O}^{-}$(Fig. 8). At $\mathrm{pH}>7.0$, most of the molecules are in anionic form (Fig. 8).

The sulfonate groups are also present in the structure of the BF-5G blue reactive dye. However, it was not possible to identify the sulphonic acid, due to the fact that this method just analyzes the $\mathrm{pH}$ in the range of 2-12. The sulfonic acids are strong acids and good donors of protons with $\mathrm{pKa}=-2.7$, i.e., in solution these groups tend to remain in their anionic form (sulfonate) conferring anionic character to the dye in solution [53]. Indeed, Errais et al. [54] observed in previous studies with the red reactive dye 120 (RR 120), whose structure also shows sulphonic acids, three different species in which the sulfonate groups were in the anionic form for the entire studied $\mathrm{pH}$ range (from 2 to 12). Thus, it can be assumed that the sulfonic acid group of the BF-5G blue reactive dye, even at $\mathrm{pH}$ equal to 2 , is in the anionic form with 4 negative sites.

\subsection{Equilibrium time for desorption}

Initially, the time required for the equilibrium between saturated bone char and the regenerating agent solution was obtained. The result is shown in Fig. 10. 


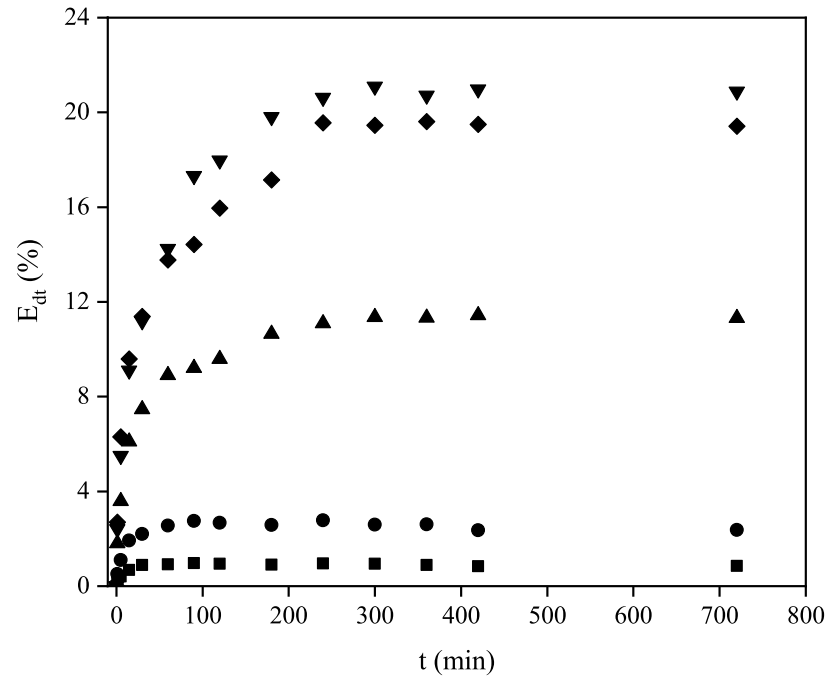

Fig. 10 Desorption kinetics of Reactive Blue BF-5G dye in bone char at $30^{\circ} \mathrm{C}$ : (filled square) deionized water; (open circle) sodium hydroxide $\left(0.1 \mathrm{~mol} \mathrm{~L}^{-1}\right)$; (filled triangle) methyl alcohol $50 \%\left(\mathrm{v} \mathrm{v}^{-1}\right)$; (filled diamond) ethyl alcohol 50\% $\left(\mathrm{v} \mathrm{v}^{-1}\right)$; and (filled inverted triangle) isopropyl alcohol $50 \%\left(v^{-1}\right)$

As shown in Fig. 10, the time to achieve the desorption equilibrium was short: approximately $2 \mathrm{~h}$ for the water and the sodium hydroxide solutions; and close to $4 \mathrm{~h}$ for other solutions of regenerating agents.

These low desorption equilibrium times, especially for the water and sodium hydroxide solutions, may be important for processes to be applicable on an industrial scale, since it could lead to a reduction in the time of adsorbent regeneration, as well as a decrease in operational costs.

We also observed that the ethyl alcohol led to a $19.49 \%$ increase in the desorption efficiency and isopropyl lead to a $20.88 \%$ increase, which corresponded to dye desorption of 20.55 and $22.02 \mathrm{mg} \mathrm{g}^{-1}$, respectively. Methyl alcohol showed intermediate behavior, with a desorption efficiency of $11.34 \%\left(11.96 \mathrm{~m} \mathrm{~g}^{-1}\right)$, whereas water and sodium hydroxide led to very low desorption efficiencies of $0.89 \%$ and $2.59 \%$, which correspond to 0.99 and $2.73 \mathrm{mg} \mathrm{g}^{-1}$, respectively. Thus, it may be concluded that organic regenerating agents are far more efficient in dye desorption than inorganic agents. The reasons for these results are discussed in detail below.

\subsection{Study of dye desorption mechanism in water}

Desorption efficiency, $\mathrm{E}_{\mathrm{eq}}(\%)$, as a function of initial water $\mathrm{pH}$ variation is shown in Fig. 11. As can be observed, the initial water $\mathrm{pH}$ influences the amount of dye desorbed from the bone char surface.

The graph presented in Fig. 11 shows that the dye desorption efficiency increases with the initial water $\mathrm{pH}$.

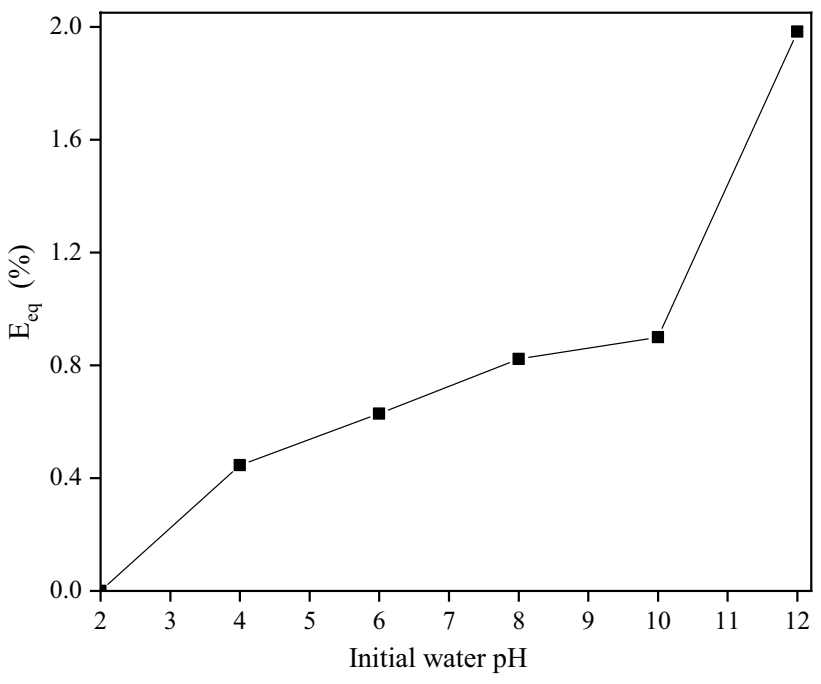

Fig. 11 Desorption efficiency of Reactive Blue BF-5G dye as a function of the initial water $\mathrm{pH}$ at $30^{\circ} \mathrm{C}$

Thereby, while there was no dye desorption in water at $\mathrm{pH} 2$, the desorption efficiency continuously increased until $\mathrm{pH} 12$, reaching a maximum value of $1.98 \%$, which corresponds to $2.09 \mathrm{mg} \mathrm{g}^{-1}$. In strong acidic solutions, i.e., significantly lower $\mathrm{pH}$ than $\mathrm{pH}_{\mathrm{PZC}}$ of $7.5 \pm 0.1$, determined for the bone char sample used (Fig. 5), the anionic dye adsorption is favored by the increasing electrostatic interaction between positive charges generated on the bone char surface [33] and the anionic group of the dye, which does not favor dye desorption. Indeed, according to Berg et al. [55] the intermolecular interactions have a much lower energy level than covalent bonds. In general, the relative bond energy follows the increasing following pattern: van der Waals forces < hydrogen bonds < electrostatic interactions. Besides, the hydrogen bonding strength may be altered due to simultaneous electrostatic interactions. Therefore, this result is in accordance with the potencial electrostatic map presented in Figs. 6 and $9(\mathrm{pKa}=4.6)$. On the other hand, when the $\mathrm{pH}$ is higher than $\mathrm{pH}_{\mathrm{PZC}}=7.5$, the alkalinity favors the appearance of negative charges on the bone char surface, increasing the anionic dye repulsion and, consequently, favoring desorption. This results is corroborated by the potential electrostatic maps showed in Figs. 7 and 8 that indicates the prevalence of negative character in the dye molecule at $\mathrm{pH}$ higher or equal to 7. Indeed, according to Mahmoodi et al. [21], as the pH of a system increases, the number of sites with negative charge also increases, favoring the anionic dye desorption resulting from electrostatic repulsion. According to Scheufele et al. [56], in a multilayer adsorption which is characterized by specific features due to the absence or the decrease in the electrostatic interactions of the adsorbed-adsorbed type between the dye molecules, other weak interactions 
are process-drives, such as the hydrophobic interactions and van der Waals forces [57]. Although the desorption efficiency increased with increasing $\mathrm{pH}$, the increment was small, showing that changing the initial water $\mathrm{pH}$ has a litlle effect on the desorption efficiency. This indicates that changing from an acid to basic medium is not sufficient to break the strong interactions formed between the dye and bone char. These results emphasize the importance of investigating more efficient regenerating agents. A schematic representation of the dye desorption mechanism in these conditions is shown in Fig. 12.

\subsection{Study of dye desorption mechanism in organic and inorganic regenerating agent}

According to Lu et al. [22], the initial concentration of the chemical regenerating agent may increase the desorption efficiency. Therefore, experiments with different initial concentrations of inorganic and organic regenerating agents were performed in order to investigate the possible desorption mechanism in these media and its influence on the dye desorption efficiency. The result obtained with sodium hydroxide as an inorganic regenerating agent is shown in Fig. 13.

As observed in Fig. 13, the dye desorption efficiency using a $0.1 \mathrm{~mol} \mathrm{~L}^{-1}$ solution of $\mathrm{NaOH}$ was very low $\left(E_{d c}=2.7 \%\right.$, initial $\left.p H=13.5\right)$. As the sodium hydroxide concentration increases, the solution $\mathrm{pH}$ also increases. Thus, it was expected that solutions with higher basicity would lead to an effective desorption of the dye on bone char. As the solid surface becomes negatively charged, there would be an increase in the electrostatic dye repulsion, as previously discussed (Figs. 6 up to 8).

According to Mall et al. [58], strong acids, such as $\mathrm{HCl}$ or $\mathrm{HNO}_{3}$, or strong bases, such as $\mathrm{NaOH}$, can promote dye

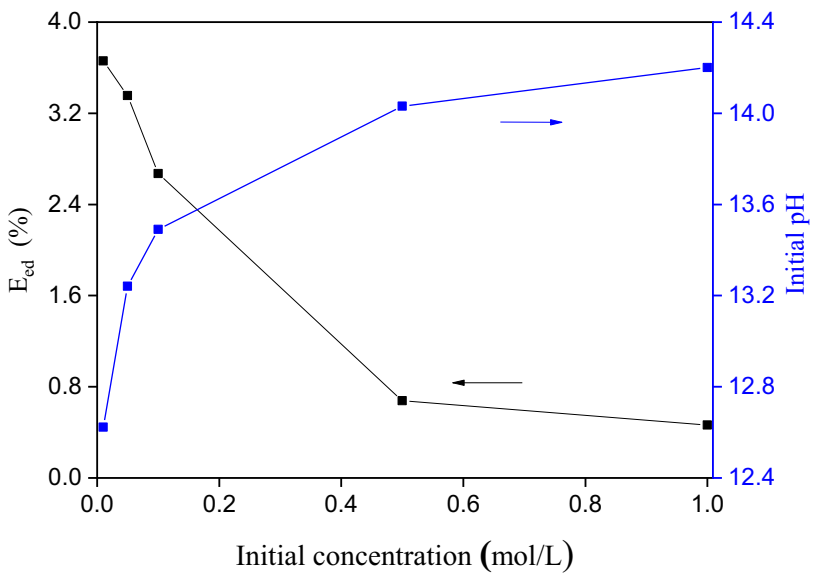

Fig. 13 Desorption efficiency of Reactive Blue BF-5G dye as a function of the initial concentration of sodium hydroxide solutions at $30^{\circ} \mathrm{C}$

desorption. Indeed, Namasivayam et al. [59] performed the adsorption of two anionic dyes: Direct Red and Acid Brilliant Blue. It was observed that adsorption increased in acidic solutions and desorption in alkaline solutions. According to the authors, their findings explain that those dyes are most likely retained by a strong interaction of ion exchange. Similar results were found by Sivaraj et al. [60]. However, the dissociation of the molecules in strong acids and bases, such as $\mathrm{NaOH}$ and $\mathrm{HCl}$, occurs in aqueous solution, and the ions $\mathrm{Na}^{+}, \mathrm{OH}^{-}, \mathrm{H}^{+}$, and $\mathrm{Cl}^{-}$may compete for positively or negatively charged adsorption sites on the bone char surface, affecting the nature of the adsorbent surface [61]. In agreement, Leng and Pinto [16] studied the chemical regeneration of activated carbon saturated with different adsorbates. It was observed that for activated carbon saturated with phenol, aniline, and benzoic
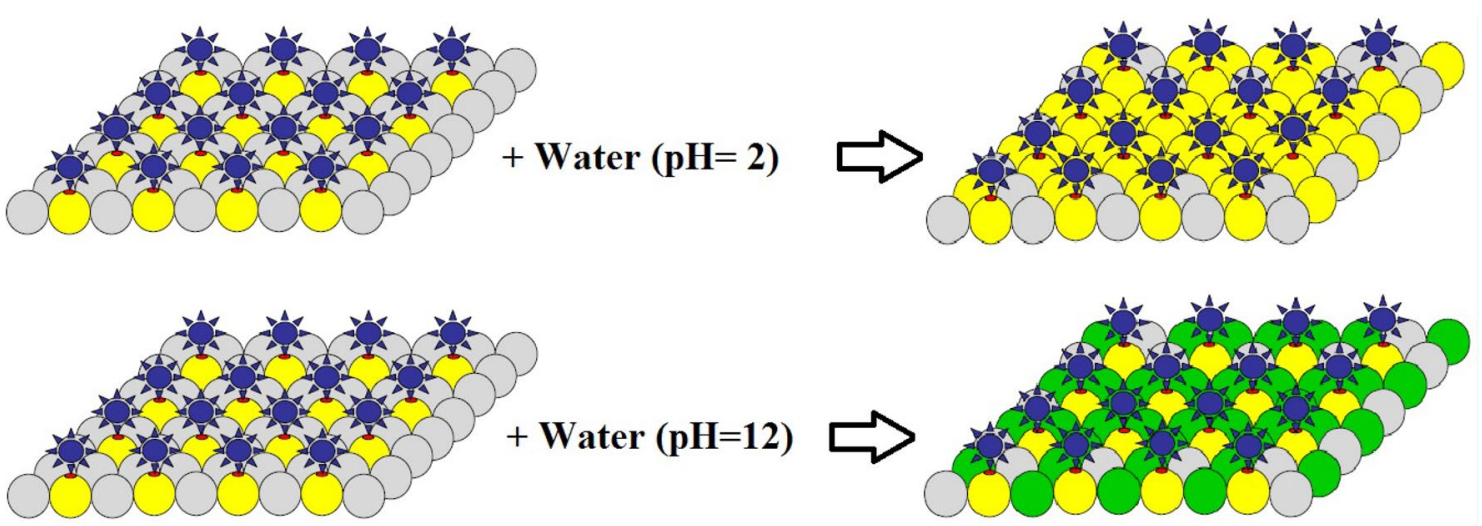

Dye

Positive charge

Negative charge

Fig. 12 Schematic representation for Reactive Blue BF-5G dye desorption mechanism of bone char using water 
acid, the increase on the initial concentration of $\mathrm{NaOH}$ resulted in a decrease in desorption efficiency. This $\mathrm{NaOH}$ dependence can be attributed to the higher adsorption of $\mathrm{OH}^{-}$at higher concentrations of $\mathrm{NaOH}$, which inhibits the desorption process.

As shown in Fig. 13, the desorption efficiency of the dye decreased with increasing sodium hydroxide concentration. At higher concentrations, the initial $\mathrm{pH}$ was higher (for $1 \mathrm{~mol} \mathrm{~L}^{-1} \mathrm{NaOH}$ solution, $\mathrm{pH}=14.2$ ). This increase in $\mathrm{pH}$ generated negative charges on the bone char surface, increasing the repulsion between the dye and adsorbent. Thus, as discussed, it is believed that the excess of $\mathrm{Na}^{+}$ions within the solution would neutralize the surface negative charges thus, reducing the electrostatic repulsion between the dye and the bone char. As a consequence, dye molecules remained adsorbed onto the bone char surface. Therefore, sodium hydroxide was not effective in promoting the dye desorption, since the higher desorption efficiency observed was only $3.66 \%$, obtained using a very low initial concentration of $0.01 \mathrm{~mol} \mathrm{~L}^{-1}$. A schematic representation of the dye desorption mechanism at a low $\mathrm{NaOH}$ concentration $\left(0.01 \mathrm{~mol} \mathrm{~L}^{-1}\right)$ and a high $\mathrm{NaOH}$ concentration $\left(1 \mathrm{~mol} \mathrm{~L}^{-1}\right)$ are shown in Fig. 14.

As already shown in Fig. 10, organic regenerating agents have a higher capacity to promote dye desorption from the bone char surface. A more accurate analysis is shown in Fig. 15, which depicts the dye desorption efficiency as a function of the initial concentration of the organic regenerating agents.

It was observed that the most efficient desorption process was achieved by using alcoholic solutions. The concentration of each regenerating agent that favored the desorption process was $50 \%\left(v^{-1}\right)$ for isopropyl alcohol, 50\% $\left(\mathrm{v} \mathrm{v}^{-1}\right)$ for ethyl alcohol and $80 \%\left(\mathrm{v} \mathrm{v}^{-1}\right)$ for

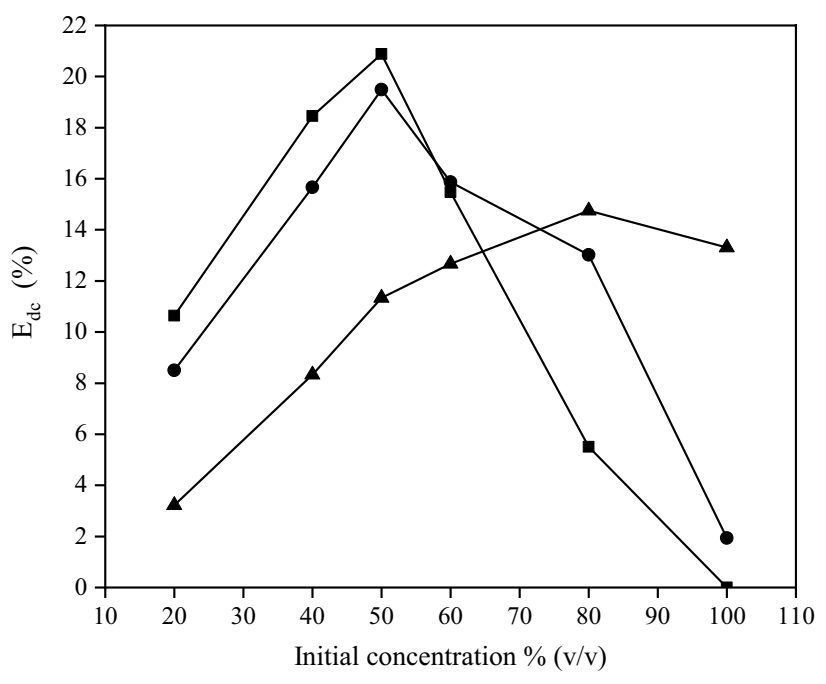

Fig. 15 Desorption efficiency of Reactive Blue BF-5G dye as a function of the initial concentration of organic regenerating agent at $30{ }^{\circ} \mathrm{C}$ : (filled triangle) methyl alcohol; (filled circle) ethyl alcohol; and (filled square) isopropyl alcohol

methyl alcohol, with dye desorption efficiencies of $20.88 \%$, $19.49 \%$, and $14.75 \%$, respectively. Thus, the results indicate that the solvents have high efficiency in alcoholic solutions and low efficiency when highly concentrated alcohols are used. Some published results in literature agree with the results presented herein. Lu et al. [22] studied the desorption of anionic dyes in coconut shell activated carbon using isopropyl alcohol and acetone as regenerating agents. The best desorption efficiency was obtained with $40 \%\left(v^{-1}\right)$ isopropyl alcohol for Mustard Yellow dye and $60 \%\left(v^{-1}\right)$ acetone for Peach Red dye.

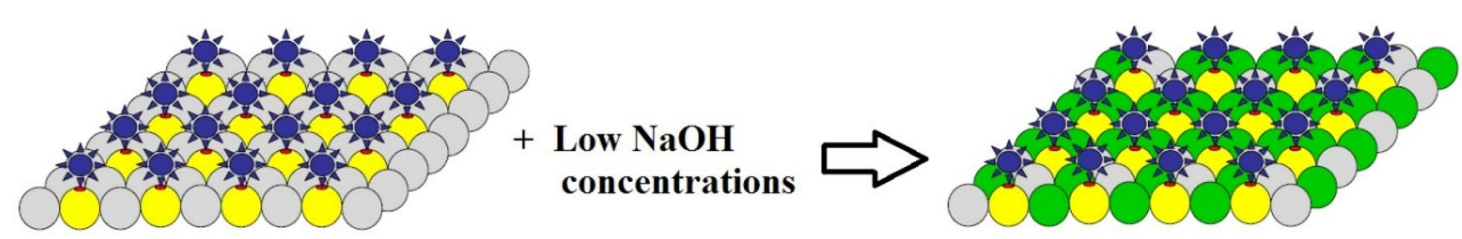

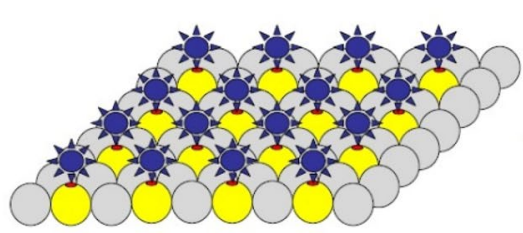

+ High $\mathrm{NaOH}$ concetrations
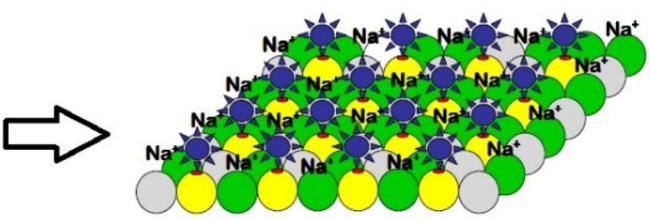

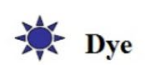

Positive charge

Negative charge

$\mathrm{Na}^{+}$Sodium

Fig. 14 Schematic representation of the Reactive Blue BF-5G desorption mechanism of bone char using $\mathrm{NaOH}$ as regenerating agent 
The dye molecule average diameter and the electronegativity of the hydroxy group are important factors to be considered during the sorption process. In this sense, molecules with greater diameter experience diffusional resistance when moving though the pores of the adsorbent [62-64]. For this reason, considering all the regenerating agents used, methanol presented higher changes of diffusing through the adsorbent since it has the shortest carbon chain from and the highest electronegativity [65].

Besides, one of the characteristics of organic regenerating agents that may affect the desorption process is their hydrophobicity [22]. The partition coefficients of methanol, ethanol, and isopropanol are $0.15,0.48$, and 2.19, respectively. A regenerating agent with higher partition coefficient is more hydrophobic. Therefore, it is expected that a competition occurs between the alcohol and the dye molecule for adsorption sites on the bone char surface. As the isopropyl and ethyl alcohols are more hydrophobic than methyl alcohol, it is believed that these two compounds cause a higher competition between the dye molecules and the regenerating agent for the adsorption sites, leading to a higher desorption efficiency.

According to results shown in Fig. 15, it was found that the highest desorption efficiencies were obtained using ethanol (19.49\%) and isopropanol (20.88\%). However, it is necessary to emphasize that the values of desorption efficiency obtained were still low. A schematic representation of the dye desorption mechanism using organic regenerating agents is shown in Fig. 16.

According to Çelekli et al. [66], the reversibility of the adsorption process depends on the existence of strong interactions (e.g. ionic or covalent) or weak interactions (e.g. Van der Waals forces or dipole-dipole interactions) that are formed between the dye molecules and the adsorbent surface. Therefore, the low values of desorption efficiency indicated that the reversibility of the adsorption was associated with the fact that they show strong interactions between the dye and the bone char surface, which is a characteristic of chemisorption. Thus, the regenerating agents studied in this work were not able to break all the strong interactions between dye and the active sites of the bone char. These solvents probably regenerated only the weak interactions on the adsorbent surface.

Samples saturated with dye and desorbed with the ethanol and isopropanol regenerating agents were analyzed by FTIR, as described early, and the spectra obtained are shown in Fig. 17.

The $-\mathrm{OH}$ stretching vibration band was observed at $3431 \mathrm{~cm}^{-1}[67,68]$. The band observed at $1038 \mathrm{~cm}^{-1}$ was attributed to the $\mathrm{P}-\mathrm{O}$ stretching vibrations of $\mathrm{PO}_{4}{ }^{-3}$ group $[69,70]$. The band at $579 \mathrm{~cm}^{-1}$ corresponds to $\mathrm{PO}_{4}{ }^{-3}$ bending vibrations, a feature of the hydroxyl group interaction with phosphate [71, 72]. These bands are typically found in hydroxyapatite, which was evident in all samples.

The bonds vibrations of $\mathrm{C}=\mathrm{O}$ and $\mathrm{CO}_{3}{ }^{2-}$ were observed at $1446 \mathrm{~cm}^{-1}$, and are related to the carbonate group linked with $\mathrm{Ca}^{2+}$ by structural hydroxyapatite [73]. These band signals corroborated the $\mathrm{X}$-ray diffraction peak (Fig. 5) regarding the mineral calcite $\left(\mathrm{CaCO}_{3}\right)$.

After desorption of the dye molecules (Fig. 17 spectra c and d), one additional band was observed at $2347 \mathrm{~cm}^{-1}$ in comparison with the parent bone char sample (Fig. 17

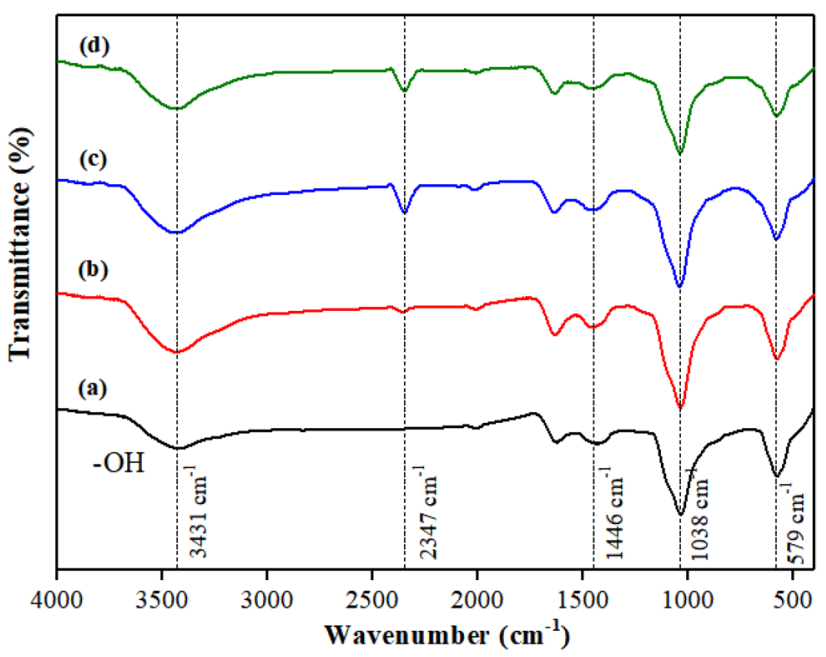

Fig. 17 FTIR spectra of bone char: (a) parent sample; (b) saturated with Reactive Blue BF-5G dye; desorbed with (c) ethyl alcohol and (d) isopropyl alcohol
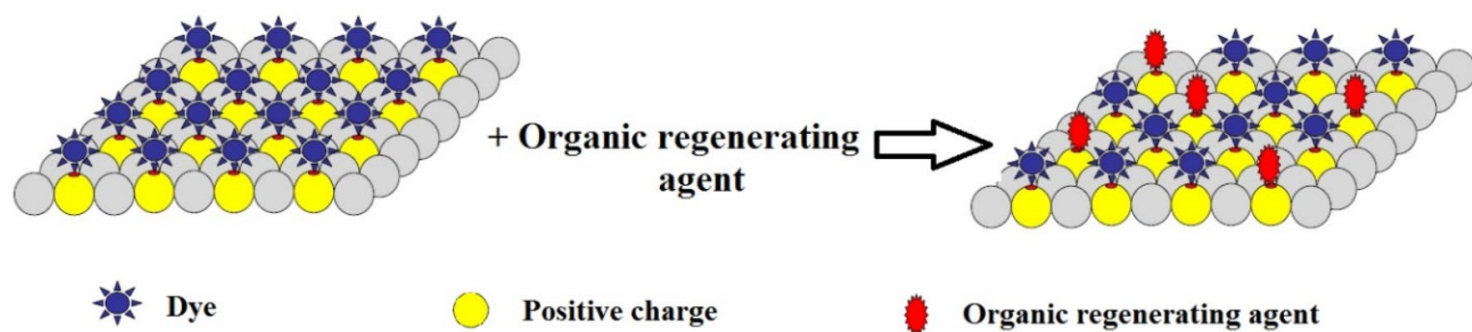

Positive charge

Organic regenerating agent

Fig. 16 Schematic representation of the Reactive Blue BF-5G desorption mechanism of bone char with organic regenerating agents 
spectrum a). This change in intensity may suggest that the characteristic group can either be $\mathrm{S}-\mathrm{H}$ or $\mathrm{C}-\mathrm{S}$ bonds [74] being, nevertheless, an evidence for the interaction between the carbon and the hydroxyl from the alcoholic molecules or with sulfur from bone char.

Reynel-Avila et al. [75] proposed that anionic dyes ionize in aqueous solution to form negatively charged molecule and the main surface interactions between dye molecules and bone char could be described according to Eq. 4.

$\equiv \mathrm{SOH}_{2}^{+}+\mathrm{SO}_{3}^{-}($dye $) \rightarrow \equiv \mathrm{SOH}_{2}-\mathrm{SO}_{3}($ dye $)$

where $\equiv \mathrm{S}$ represents the bone char surface adsorption sites.

This proposal agrees with the explanation for desorption results and mechanism proposed herein (Fig. 16), in which the desorption occurs through replacement of the dye by alcohol molecules and it can be represented as shown in Eq. 5.

$$
\begin{gathered}
\equiv \mathrm{SOH}_{2}-\mathrm{SO}_{3}(\text { dye })+: \text { ÖH }(\text { alcohol }) \rightarrow \\
\mathrm{SOH}_{2}-\mathrm{OH}(\text { alcohol })+\mathrm{SO}_{3}^{-}(\text {dye })
\end{gathered}
$$

\section{Conclusions}

The results show that the different regenerating agents may act in different ways in dye desorption. An increase in initial water $\mathrm{pH}$ leads to an increase in the desorption efficiency due to higher amount of negative charges on the surface of the bone char, thus generating electrostatic repulsion between the dye molecules and the bone char surface. In the case of sodium hydroxide, an increase in the concentration of the inorganic regenerating agent causes a reduction in desorption efficiency due to compensation of the negative charges of bone char by the excess of $\mathrm{Na}^{+}$ions present in the solution. In the case of organic regenerating agents, the desorption mechanism is due to the replacement of dye molecules by alcohol molecules. Therefore, the results obtained in this work show that initial water $\mathrm{pH}$ has little influence on the desorption process and sodium hydroxide give negligible desorption efficiency as well. The highest desorption efficiencies are obtained using isopropyl (20.88\%) and ethyl (19.49\%) alcohols, respectively. The results also show that the dye adsorption mechanism occurs predominantly through strong interactions, although weak interactions also occur and cannot be undervalued. As a consequence, only the weak interactions between dye and bone char surface are regenerated using the agents studied herein.
Acknowledgements The authors acknowledge the Coordination for the Improvement of Higher Education Personnel (CAPES) and National Council for Scientific and Technological Development (CNPq) for financial support and fellowship.

Conflict of interest All authors approved the manuscript, this submission and state that there is no conflict of interests associated with this publication. This manuscript describes an original work, has not been published before and is not under consideration by any other journal.

\section{References}

1. Rangabhashiyam S, Anu N, Selvaraju N (2013) Sequestration of dye from textile industry wastewater using agricultural waste products as adsorbents. J Environ Chem Eng 1(4):629-641

2. Mahmoud DK, Salleh MAM, Karim WAWA, Idris A, Abidin ZZ (2012) Batch adsorption of basic dye using acid treated kenaf fiber char: equilibrium, kinetic and thermodynamic studies. Chem Eng J 181:449-457

3. Ahmad MA, Rahman NK (2011) Equilibrium, kinetics and thermodynamic of Remazol Brilliant Orange 3R dye adsorption on coffee husk-based activated carbon. Chem Eng J 170(1):154-161

4. Ip AWM, Barford JP, McKay G (2009) Reactive black dye adsorption/desorption onto different adsorbents: effect of salt, surface chemistry, pore size and surface area. J Colloid Interface Sci 337(1):32-38

5. Gupta VK, Mittal A, Malviya A, Mittal J (2009) Adsorption of carmoisine a from wastewater using waste materials - bottom ash and deoiled soya. J Colloid Interface Sci 335(1):24-33

6. Jana S, Ray J, Mondal B, Pradhan SS, Tripathy T (2018) pH responsive adsorption/desorption studies of organic dyes from their aqueous solutions by Katira gum-cl-poly (acrylic acid-co-N-vinyl imidazole) hydrogel. Colloids Surf A Physicochem Eng Asp 553:472-486

7. Demirbas A (2009) Agricultural based activated carbons for the removal of dyes from aqueous solutions: a review. J Hazard Mater 167(1-3):1-9

8. Gautam RK, Mudhoo A, Chattopadhyaya MC (2013) Kinetic, equilibrium, thermodynamic studies and spectroscopic analysis of Alizarin Red S removal by mustard husk. J Environ Chem Eng 1(4):1283-1291

9. Al-Degs YS, El-Barghouthi MI, El-Sheikh AH, Walker GM (2008) Effect of solution $\mathrm{pH}$, ionic strength, and temperature on adsorption behavior of reactive dyes on activated carbon. Dyes Pigments 77(1):16-23

10. Ahmed MJ, Dhedan SK (2012) Equilibrium isotherms and kinetics modeling of methylene blue adsorption on agricultural wastes-based activated carbons. Fluid Phase Equilib 317:9-14

11. Ip AW, Barford JP, McKay G (2010) A comparative study on the kinetics and mechanisms of removal of reactive black 5 by adsorption onto activated carbons and bone char. Chem Eng J 157(2-3):434-442

12. Belaid KD, Kacha S, Kameche M, Derriche Z (2013) Adsorption kinetics of some textile dyes onto granular activated carbon. J Environ Chem Eng 1(3):496-503

13. Ofomaja $A E$, Ho YS (2007) Equilibrium sorption of anionic dye from aqueous solution by palm kernel fibre as sorbent. Dyes Pigments 74(1):60-66

14. Sabio E, González E, González JF, González-Garcia CM, Ramiro A, Ganan J (2004) Thermal regeneration of activated carbon saturated with p-nitrophenol. Carbon 42(11):2285-2293 
15. Shende RV, Mahajani VV (2002) Wet oxidative regeneration of activated carbon loaded with reactive dye. Waste Manag 22(1):73-83

16. Leng CC, Pinto NG (1996) An investigation of the mechanisms of chemical regeneration of activated carbon. Ind Eng Chem Res 35(6):2024-2031

17. Sajab MS, Chia CH, Zakaria S, Khiew PS (2013) Cationic and anionic modifications of oil palm empty fruit bunch fibers for the removal of dyes from aqueous solutions. Bioresour Technol 128:571-577

18. Brown MA, De Vito SC (1993) Predicting azo dye toxicity. Crit Rev Environ Sci Technol 23(3):249-324

19. Lim JL, Okada M (2005) Regeneration of granular activated carbon using ultrasound. Ultrason Sonochem 12(4):277-282

20. Cooney DO, Nagerl A, Hines AL (1983) Solvent regeneration of activated carbon. Water Res 17(4):403-410

21. Mahmoodi NM, Hayati B, Arami M, Lan C (2011) Adsorption of textile dyes on pine cone from colored wastewater: kinetic, equilibrium and thermodynamic studies. Desalination 268(1-3):117-125

22. Lu PJ, Lin HC, Yu WT, Chern JM (2011) Chemical regeneration of activated carbon used for dye adsorption. J Taiwan Inst Chem Eng 42(2):305-311

23. Maeda $\mathrm{CH}$, Araki CA, Moretti AL, de Barros MASD, Arroyo PA (2018) Adsorption and desorption cycles of reactive blue BF-5G dye in a bone char fixed-bed column. Environ Sci Pollut Res 26(28):28500-28509, 2019

24. Gupta VK, Gupta B, Rastogi A, Agarwal S, Nayak A (2011) A comparative investigation on adsorption performances of mesoporous activated carbon prepared from waste rubber tire and activated carbon for a hazardous azo dye-acid blue 113 . J Hazard Mater 186(1):891-901

25. Mittal A, Mittal J, Kurup L (2006) Batch and bulk removal of hazardous dye, indigo carmine from wastewater through adsorption. J Hazard Mater 137(1):591-602

26. Talaiekhozani A, Torkan N, Banisharif F, Eskandari Z, Rezania S, Park J, Amisharei F, Amani AM (2018) Comparison of reactive blue 203 dye removal using ultraviolet irradiation, ferrate (VI) oxidation process and $\mathrm{MgO}$ nanoparticles. Avicenna J Environ Health Eng 5(2):78-90

27. Talaiekhozani A, Banisharif F, Eskandari Z, Heydari Chaleshtari A, Moghadam G, Amani AM (2019) Comparing the ZnO/Fe (VI), UV/ $\mathrm{ZnO}$ and $\mathrm{UV} / \mathrm{Fe}(\mathrm{VI})$ processes for removal of reactive blue 203 from aqueous solution. Environ Health Eng Manage J 6(1):27-39

28. Salleh MAM, Mahmoud DK, Karim WAWA, Idris A (2011) Cationic and anionic dye adsorption by agricultural solid wastes: a comprehensive review. Desalination 280(1-3):1-13

29. Regalbuto JR, Robles J (2004) The engineering of Pt/carbon catalyst preparation. University of Illinois, Chicago

30. Barca GMJ et al (2020) Recent developments in the general atomic and molecular electronic structure system. J Chem Phys 152(15):154102

31. Young D (2001) Computational chemistry: a practical guide for applying techniques to real world problems. John Wiley \& Sons

32. Foresman JB, Frish A (1996) Exploring chemistry with electronic structure methods, 2nd edn. Gaussian Inc, Pitsburg

33. Skoog DA, West DM, Holler FJ, Crouch SR (2006) Fundamentals of analytical chemistry. Brooks/Cole

34. Vytřas K, Kalous J, Šilená-Jirásková I (1993) Potentiometric titrations of some o, o'-substituted acid azo dyes. Dyes Pigments 23(1):43-51

35. Mäntele W, Deniz E (2017) UV-VIS absorption spectroscopy: Lambert-Beer reloaded. Spectrochim Acta A Mol Biomol Spectrosc 173:965-968
36. Robinson T, Chandran B, Nigam P (2002) Studies on desorption of individual textile dyes and a synthetic dye effluent from dyeadsorbed agricultural residues using solvents. Bioresour Technol 84(3):299-301

37. Mittal A, Mittal J, Malviya A, Gupta VK (2010) Removal and recovery of Chrysoidine $Y$ from aqueous solutions by waste materials. J Colloid Interface Sci 344(2):497-507

38. Cheung CW, Porter JF, McKay G (2002) Removal of Cu (II) and Zn (II) ions by sorption onto bone char using batch agitation. Langmuir 18(3):650-656

39. Choy KK, McKay G (2005) Sorption of cadmium, copper, and zinc ions onto bone char using crank diffusion model. Chemosphere 60(8):1141-1150

40. Zhao J, Yu L, Ma H, Zhou F et al (2020) Corn stalk-based activated carbon synthesized by a novel activation method for high-performance adsorption of hexavalent chromium in aqueous solutions. J Colloid Interface Sci 578:650-659

41. Wang H, Li X, Cui Z, Fu Z et al (2020) Coffee grounds derived $\mathrm{N}$-enriched microporous activated carbons: efficient adsorbent for post-combustion CO2 capture and conversion. J Colloid Interface Sci 578:491-499

42. Medellín-Castillo NA, Cruz-Briano SA, Leyva-Ramos R, MorenoPiraján JC et al (2020) Use of bone char prepared from an invasive species, pleco fish (Pterygoplichthys spp.), to remove fluoride and Cadmium(II) in water. J Environ Manag 256:109956

43. Alkurdi SSA, Al-Juboori RA, Bundschuh J, Bowtell L, McKnight $S$ (2020) Effect of pyrolysis conditions on bone char characterization and its ability for arsenic and fluoride removal. Environ Pollut 262:114221

44. Flores-Cano JV, Leyva-Ramos R, Carrasco-Marin F, Aragón-Piña A, Salazar-Rabago JJ, Leyva-Ramos S (2016) Adsorption mechanism of Chromium (III) from water solution on bone char: effect of operating conditions. Adsorption 22(3):297-308

45. Shahid MK, Kim JY, Choi YG (2019) Synthesis of bone char from cattle bones and its application for fluoride removal from the contaminated water. Groundw Sustain Dev 8:324-331

46. Patel S, Han J, Qiu W, Gao W (2015) Synthesis and characterisation of mesoporous bone char obtained by pyrolysis of animal bones, for environmental application. J Environ Chem Eng 3(4):2368-2377

47. de Melo NH, de Oliveira Ferreira ME, Neto EMS, Martins PR, Ostroski IC (2018) Evaluation of the adsorption process using activated bone char functionalized with magnetite nanoparticles. Environ Nanotechnol Monitor Manage 10:427-434

48. Glaesner N, Hansen HCB, Hu Y, Bekiaris G, Bruun S (2019) Low crystalline apatite in bone char produced at low temperature ameliorates phosphorus-deficient soils. Chemosphere 223:723-730

49. Rojas-Mayorga CK, Mendoza-Castillo DI, Bonilla-Petriciolet A, Silvestre-Albero J (2016) Tailong the adsorption behavior of bone char for heavy metal removal from aqueous solution. Adsorpt Sci Technol 34(60):368-387

50. Thommes M, Kaneko K, Neimark AV, Olivier JP, Rodriguez-Reinoso F, Rouquerol J, Sing KS (2015) Physisorption of gases, with special reference to the evaluation of surface area and pore size distribution (IUPAC Technical Report). Pure Appl Chem 87(9-10):1051-1069

51. Leyva-Ramos R, Rivera-Utrilla J, Medellin-Castillo NA, SanchezPolo M (2010) Kinetic modeling of fluoride adsorption from aqueous solution onto bone char. Chem Eng J 158(3):458-467

52. Barret R (2018) Importance and evaluation of the pka. In: Therapeutical chemistry fundamentals. Elsevier, Amsterdam, pp 21-51

53. Monte-Blanco SPD, Scheufele FB, Módenes AN, EspinozaQuiñones FR, Marin P, Kroumov AD, Borba CE (2017) Kinetic, 
equilibrium and thermodynamic phenomenological modeling of reactive dye adsorption onto polymeric adsorbent. Chem Eng J 307:466-475

54. Errais E, Duplay J, Elhabiri M, Khodja M, Ocampo R, BaltenweckGuyot R, Darragi F (2012) Anionic RR120 dye adsorption onto raw clay: surface properties and adsorption mechanism. Colloids Surf A Physicochem Eng Asp 403:69-78

55. Berg JM, Tymoczko JL, Stryer L (2002) Section 8.4 - the Michaelis-Menten model accounts for the kinetic properties of many enzymes. In: Biochemistry, 5th edn. WH Freeman, New York

56. Scheufele FB, Módenes AN, Borba CE, Ribeiro C, EspinozaQuiñones FR, Bergamasco R, Pereira NC (2016) Monolayer-multilayer adsorption phenomenological model: kinetics, equilibrium and thermodynamics. Chem Eng J 284:1328-1341

57. Coates $E$ (1969) Aggregation of dyes in aqueous solutions. J Soc Dye Colour 85(8):355-368

58. Mall ID, Srivastava VC, Kumar GVA, Mishra IM (2006) Characterization and utilization of mesoporous fertilizer plant waste carbon for adsorptive removal of dyes from aqueous solution. Colloids Surf A Physicochem Eng Asp 278(1-3):175-187

59. Namasivayam C, Prabha D, Kumutha M (1998) Removal of direct red and acid brilliant blue by adsorption on to banana pith. Bioresour Technol 64(1):77-79

60. Sivaraj R, Namasivayam C, Kadirvelu K (2001) Orange peel as an adsorbent in the removal of acid violet 17 (acid dye) from aqueous solutions. Waste Manag 21(1):105-110

61. Martin RJ, Ng WJ (1984) Chemical regeneration of exhausted activated carbon-I. Water Res 18(1):59-73

62. Heinonen J, Sainio T (2013) Chromatographic fractionation of lignocellulosic hydrolysates. In: Advances in chemical engineering. Academic Press, pp 261-349

63. Helfferich F (1995) Ion exchange. Dower Publications Inc., Mineola

64. Wankat PC (1990) Rate-controlled separations, Essex. Elsevier Science Publishers Ltd, Great Britain

65. Chakraborty S, Bera R, Mandal A, Dey A, Chakrabarty D, Rene ER, Lens PN (2019) Adsorption removal of alcohols from aqueous solutions by $\mathrm{N}$-tertiary-butylacrylamide (NtBA) and acrylic acid co-polymer gel. Mater Today Commun 21:100653

66. Çelekli A, Tanrıverdi B, Bozkurt H (2011) Predictive modeling of removal of Lanaset Red G on Chara contraria; kinetic, equilibrium, and thermodynamic studies. Chem Eng J 169(1-3):166-172
67. Silverstein RM, Webster FX, Kiemle DJ, Bryce DL (2014) Spectrometric identification of organic compounds. John Wiley \& Sons

68. Rojas-Mayorga CK, Silvestre-Albero J, Aguayo-Villareal IA, Mendoza-Castillo DI, Bonilla-Petriciolet A (2015) A new synthesis route for bone chars using $\mathrm{CO}_{2}$ atmosphere and their application as fluoride adsorbents. Microporous Mesoporous Mater 209:38-44

69. Rojas-Mayorga CK, Bonilla-Petriciolet A, Aguayo-Villareal IA, Hernández-Montoya V, Moreno-Virgen MR, Tovar-Gómez R, Montes-Morán MA (2013) Optimization of pyrolysis conditions and adsorption properties of boné char for fluoride removal from water. J Anal Appl Pyrolysis 104:10-18

70. Brum RF, Marinuchi R, Gomes JM, Conceição I, Ostroski PAA, Tavares CRG, Barros MASD (2010) Equilibrium studies of Mn (II), $\mathrm{Pb}$ (II) and $\mathrm{Cr}$ (III) in bone char. Chem Eng 21:721-726

71. Farmer VC (1974) Infrared spectra of minerals. Mineralogical Society

72. Nakamoto K (1977) Infrared and Raman spectra of inorganic and coordination compounds. Wiley

73. Rojas-Mayorga CK, Bonilla-Petriciolet A, Silvestre-Albero J, Aguayo-Villarreal IA, Mendoza-Castillo DI (2015) Physicochemical characterization of metal-doped bone chars and their adsorption behavior for water defluoridation. Appl Surf Sci 355:748-760

74. Adi-Dako O, Ofori-Kwakye K, Frimpong Manso S, Boakye-Gyasi ME, Sasu C, Pobee M (2016) Physicochemical and antimicrobial properties of cocoa pod husk pectin intended as a versatile pharmaceutical excipient and nutraceutical. J Pharm:2016

75. Reynel-Avila HE, Mendoza-Castillo DI, Bonilla-Petriciolet A (2016) Relevance of anionic dye properties on water decolorization performance using bone char: adsorption kinetics, isotherms and breakthrough curves. J Mol Liq 219:425-434

Publisher's Note Springer Nature remains neutral with regard to jurisdictional claims in published maps and institutional affiliations. 